\title{
Energy-based control of a DC Modular Multilevel Converter for HVDC grids
}

\begin{tabular}{|c|c|}
\hline Journal: & IEEE Transactions on Power Delivery \\
\hline Manuscript ID & TPWRD-00435-2019.R2 \\
\hline Manuscript Type: & Transactions \\
\hline $\begin{array}{r}\text { Date Submitted by the } \\
\text { Author: }\end{array}$ & 05-Nov-2019 \\
\hline Complete List of Authors: & $\begin{array}{l}\text { Cheah-Mane, Marc; CITCEA-UPC, } \\
\text { Arevalo-Soler, Josep; CITCEA-UPC } \\
\text { Prieto Araujo, Eduardo; CITCEA-UPC } \\
\text { Gomis-Bellmunt, Oriol; CITCEA-UPC }\end{array}$ \\
\hline Technical Topic Area : & HVDC transmission and distribution < Transmission and Distribution \\
\hline Key Words: & HVDC converters, DC-DC power conversion, Control systems \\
\hline
\end{tabular}

\section{SCHOLARONE ${ }^{\text {TH }}$ Manuscripts}




\title{
Energy-based control of a DC Modular Multilevel Converter for HVDC grids
}

\author{
Marc Cheah-Mane, Member, IEEE, Josep Arevalo-Soler, Eduardo Prieto-Araujo, Member, IEEE, \\ and Oriol Gomis-Bellmunt, Senior Member, IEEE
}

\begin{abstract}
DC-DC converters are expected to interconnect High Voltage Direct Current (HVDC) grids with different configurations or voltage levels, which will increase reliability and operational flexibility. The DC Modular Multilevel Converter (DC-MMC) is suggested as a potential non-isolated topology for HVDC applications. This paper presents an energy-based closedloop control for the DC-MMC. Such control structure provides a full control of the current components, while ensuring energy balancing in normal and fault operation

First, the converter configuration is described and the fundamental equations are presented. Then, the normal operation of the converter is explained from the steady state conditions and the energy and current components. A closed-loop control is designed to ensure a proper dynamic response, balance the internal energies of the converter and minimize the $\mathrm{AC}$ circulating current. Also, the control structure is modified to ensure DC fault ride through capability. Simulation results in Matlab Simulink are used to validate the converter control under normal operation and DC faults.
\end{abstract}

Index Terms-HVDC, DC-DC converter, MMC, DC faults

\section{INTRODUCTION}

$\mathbf{H}$ IGH Voltage Direct Current (HVDC) grids have an important role in the development of the future transmission grid. Compared to HVAC transmission systems, equivalent HVDC solutions have lower line losses, do not require reactive power compensation, have longer distance limitations and offer an inherent active power control [1]. Future DC grids are expected to have different voltages levels. DC-DC converters will be used to link systems with multiple DC voltage levels, as transformers in conventional AC grids [2]. In addition, such converters can be used to increase power flow control, isolate faults and interconnect DC grids with different configurations, e.g. monopolar and bipolar systems, or different converter topologies, e.g. Line Commutated Converters (LCCs) and Voltage Source Converters (VSCs) [2].

A number of DC-DC converter topologies have been presented and compared in the literature [2]-[4]. These converters are grouped according to their galvanic isolation, i.e. are divided in two topologies: isolated and non-isolated converters. Most of the converters with galvanic isolation are based on a DC-AC-DC conversion scheme. DC-DC converters can be also classified in cell-based configurations [3].

The DC Modular Multilevel Converter (DC-MMC) analyzed in this paper is shown in Fig. 1a and represents a non-isolated and cell-based converter without transformer [5]. Potential applications of this converter include HVDC grids and DC-collection grids for offshore wind farms [5]. This topology is based on the conventional AC-DC MMC [6] and was initially presented in [7], [8]. Both AC and DC currents flow through each converter arm. DC currents are used to transfer power between the DC sides, while circulating $\mathrm{AC}$ currents are necessary to balance the energy stored in the converter submodules (SMs). Such circulating AC currents should be minimized and must not flow to the DC links, which is achieved by control actions [9].

The DC-MMC have been largely studied in the literature. Converter design considerations about the voltage ratios, operational frequency and size of the reactors and SM capacitors are detailed in [7], [9]-[14]. Basic characteristic equations and steady state analysis are presented in [7], [13], [15]-[17].

The control structure of the DC-MMC for normal operation is analyzed and implemented in [9], [11]-[16], [18]-[20]. In particular, a closed-loop control for the DC output current or power is presented in [15], [19], while [9], [13], [14], [16], [18], [20] implement an AC circulating current control. In [9], [20] an energy-based closed-loop structure with full control of current and energy components is presented using decoupled equations to simplify the modelling and control implementation as in the conventional MMC [6], [21]. Also, a number of methods to minimize AC circulating current are presented and implemented in [15], [16], [18], [19]. Finally, normal operation of the DC-MMC has been validated in a small-scale test rig by [12]-[15], [18], [19].

Operation under DC faults is discussed in [11], [18], where a DC fault blocking strategy is implemented applying a reversed voltage. However, DC current control and energy balance during fault conditions have not been analyzed in detail to the best knowledge of the authors.

This paper presents an energy-based closed-loop control for a DC-MMC that enables a full control of currents and energies in normal and fault operation. The control structure in normal operation is based on [21] for a conventional three-phase ACDC MMC. The main contribution of the paper is focused on the operation under DC fault conditions with a full control of DC current while ensuring energy balancing of the converter.

The paper starts presenting a comprehensive model of the DC-MMC, where the converter equations are decoupled following the variable definitions in [6], [21]. This approach is also used in [9], [20], but in this paper the converter currents and energy components are described in detail indicating their purpose in the global converter control for normal and fault operation. Then, the energy-based control of the DC-MMC is presented for normal and fault operation, including the design of the controllers and the calculation of the current references. In particular, DC fault ride through capability is ensured modifying the use of current components when required. As a result, DC output current is controlled and converter energy is balanced during DC faults at both sides of the converter. The 
AC circulating currents are minimized according to the angle difference between the voltage components. This improves the methods defined in [11], [18] and leads to the same optimal conditions as in [19], but without considering assumptions about the size of the reactors. In addition, a comparison with other control schemes presented in the literature is shown in detail considering several functionalities for the DC-MMC. At the end, the converter control is validated in normal operation and DC fault conditions using time-domain simulations in Matlab Simulink.

\section{SySTEM DESCRIPTION}

The configuration of the DC-MMC converter is based on the conventional three-phase AC-DC MMC as shown in Fig. 1a, where $V^{D C 1}$ is the high voltage and $V^{D C 2}$ is the low voltage.

Each converter leg has $N_{u}$ and $N_{l}$ SMs in the upper and lower arms with capacitors that are individually inserted or bypassed, such that each arm represents a controllable voltage source. This is used to control the power exchange through the converter and to balance the internal energy stored in the capacitors. The DC-MMC is modelled using an armaverage model, as shown in Fig. 1a, where the arm voltages are represented as controllable voltage sources and the SM capacitors are aggregated.

The controllable sources generate a DC voltage component equal to $V^{D C 1}-V^{D C 2}$ for the upper arms and $V^{D C 2}$ for the lower arms, which defines the voltage ratio between the DC links where the converter is connected. Also, an AC voltage component is required to balance the energy of each leg.

\section{A. Basic circuit equations}

The circuit equations per phase $j(j=a, b, c)$ are:

$$
\begin{gathered}
V^{D C 1}-V^{D C 2}-v_{u}^{j}=R_{a} i_{u}^{j}+L_{a} \frac{d i_{u}^{j}}{d t}+R_{s} i_{s}^{j}+L_{s} \frac{d i_{s}^{j}}{d t} \\
V^{D C 2}-v_{l}^{j}=R_{a} i_{l}^{j}+L_{a} \frac{d i_{l}^{j}}{d t}-R_{s} i_{s}^{j}-L_{s} \frac{d i_{s}^{j}}{d t}
\end{gathered}
$$

where $v_{u}^{j}$ and $v_{l}^{j}$ are the voltages applied by the upper and lower arms, $i_{u}^{j}$ and $i_{l}^{j}$ are the currents through the upper and lower arms, $i_{s}^{j}$ is the current through the phase reactors, $R_{a}$ and $L_{a}$ are the resistance and inductance of the arm reactors and $R_{s}$ and $L_{s}$ are the resistance and inductance of the phase reactors. The following variables and parameters are defined to simplify the converter equations as in [21]:

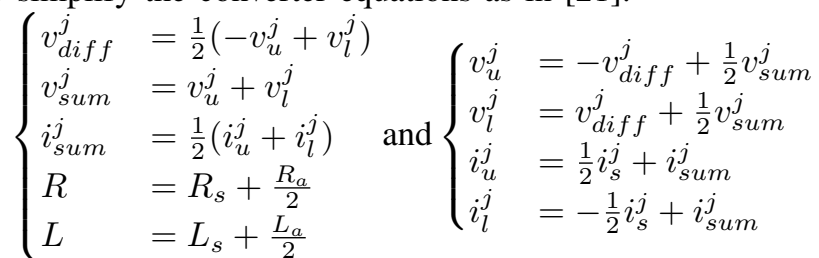

where $v_{\text {diff }}^{j}$ and $v_{\text {sum }}^{j}$ are defined as the differential and additive voltages and $i_{\text {sum }}^{j}$ is defined as the additive current through the upper and lower arms. Adding and subtracting (1) and (2) and applying the definitions in (3) the converter equations are decoupled for each DC side as follows:

$$
\begin{gathered}
v_{\text {diff }}^{j}-V^{D C 2}+\frac{V^{D C 1}}{2}=R i_{s}^{j}+L \frac{d i_{s}^{j}}{d i_{s u m}^{j l t}} \\
v_{\text {sum }}^{j}-V^{D C 1}=-2 R_{a} i_{\text {sum }}^{j}-2 L_{a} \frac{d t}{d}
\end{gathered}
$$

These decoupled equations are used to understand the DCMMC operation and implement the associated control.

\section{B. Steady-Sate analysis}

Fig. 1b shows the AC-DC voltage and current components of the DC-MMC in steady state. In particular, voltages and currents from the decoupled circuits in (4) and (5) can be expressed in steady state as follows, assuming that the AC components define a symmetrical three-phase system:

$$
\left\{\begin{array}{l}
v_{\text {diff }}^{j}=v_{\text {diff }}^{j-D C}+v_{\text {diff }}^{j-A C}=V_{\text {diff }}^{D C}+V_{\text {diff }}^{A C} \cos \left(\omega t+\phi_{\text {diff }}^{j}\right) \\
i_{s}^{j}=i_{s}^{j-D C}+i_{s}^{j-A C}=I_{s}^{D C}+I_{s}^{A C} \cos \left(\omega t+\phi_{s}^{j}\right) \\
v_{\text {sum }}^{j}=v_{\text {sum }}^{j-D C}+v_{\text {sum }}^{j-A C}=V_{\text {sum }}^{D C}+V_{\text {sum }}^{A C} \cos \left(\omega t+\phi_{\text {vsum }}^{j}\right) \\
i_{\text {sum }}^{j}=i_{\text {sum }}^{j-D C}+i_{\text {sum }}^{j-A C}=I_{\text {sum }}^{D C}+I_{\text {sum }}^{A C} \cos \left(\omega t+\phi_{\text {isum }}^{j}\right)
\end{array}\right.
$$

where $\phi_{\text {diff }}^{j}, \phi_{s}^{j}, \phi_{\text {vsum }}^{j}$ and $\phi_{\text {isum }}^{j}$ are the angle definitions of the AC components considering $\phi_{\text {diff }}^{a}=0 \mathrm{rad}$. It is assumed that second-order harmonic components are not generated in the circulating currents, $i_{\text {sum }}^{j}$, if a proper converter control is implemented. The power flow through the converter, $P$, is expressed as follows if power losses are neglected:

$$
P=V^{D C 1} I^{D C 1}=V^{D C 2} I^{D C 2}
$$

Then, the power flow between upper and lower arms is calculated as:

$$
P_{u}^{j-D C}-P_{l}^{j-D C}=\frac{2 P}{3}\left(1-\frac{V^{D C 2}}{V^{D C 1}}\right)
$$

This power is charging or discharging the upper and lower arms depending on the DC power flow direction, causing an energy imbalance in each leg. This energy deviation can be compensated using $\mathrm{AC}$ circulating currents, i.e. $i_{u}^{j-A C}$ and $i_{l}^{j-A C}$. Therefore, AC voltages, i.e. $v_{u}^{j-A C}$ and $v_{l}^{j-A C}$, must be generated within the DC-MMC in order to exchange $\mathrm{AC}$ power between the upper and lower arms and compensate the DC power component in (8). Also, AC circulating currents must be controlled such that AC homopolar components do not flow to the DC links, i.e. $i_{s}^{0-A C}=i_{u l}^{0-A C}=0$.

\section{Energy components}

The energy components are derived from the active powers of upper and lower arms. In particular, these powers are expressed in terms of the variables of the decoupled system in (6) as [6]:

$$
\left\{\begin{aligned}
P_{u}^{j}= & \left(\frac{v_{\text {sum }}^{j}}{2}-v_{\text {diff }}^{j}\right)\left(\frac{i_{s}^{j}}{2}+i_{\text {sum }}^{j}\right) \\
& =P_{u}^{j-D C}+P_{u}^{j-A C}+P_{u}^{j-\omega}+P_{u}^{j-2 \omega} \\
P_{l}^{j} & =\left(\frac{v_{\text {sum }}^{j}}{2}+v_{\text {diff }}^{j}\right)\left(-\frac{i_{s}^{j}}{2}+i_{\text {sum }}^{j}\right) \\
& =P_{l}^{j-D C}+P_{l}^{j-A C^{2}}+P_{l}^{j-\omega}+P_{l}^{j-2 \omega}
\end{aligned}\right.
$$

where $P_{u}^{j-D C}$ and $P_{l}^{j-D C}$ are constant components related to the DC variables, $P_{u}^{j-A C}$ and $P_{l}^{j-A C}$ are constant components related to the AC variables, $P_{u}^{j-\omega}$ and $P_{l}^{j-\omega}$ are periodic components at $\omega$ and $P_{u}^{2 j-\omega}$ and $P_{l}^{2 j-\omega}$ are periodic components at $2 \omega$. It should be noted that the periodic components generate power ripples at $\omega$ and $2 \omega$ that are transferred to the energy, but do not contribute to the mean value of upper and lower arm energies, $E_{u}^{j}$ and $E_{l}^{j}$.

The converter energy is divided in three components: 


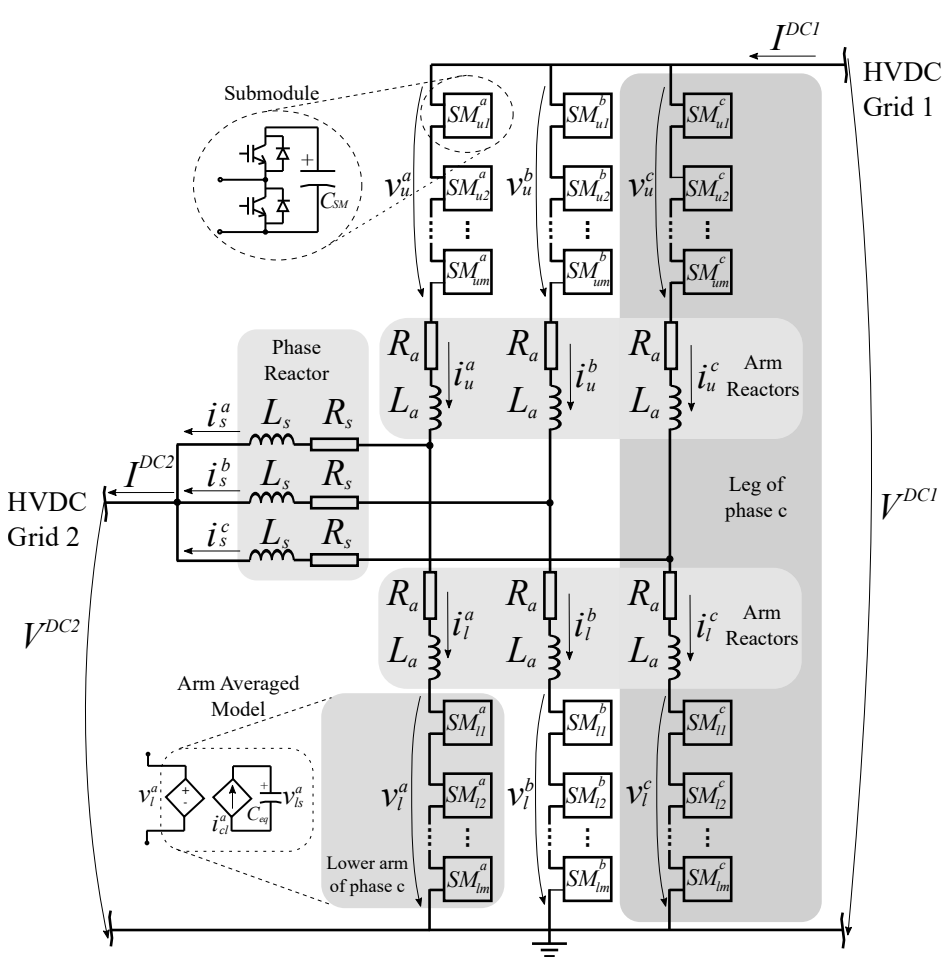

(a) General scheme

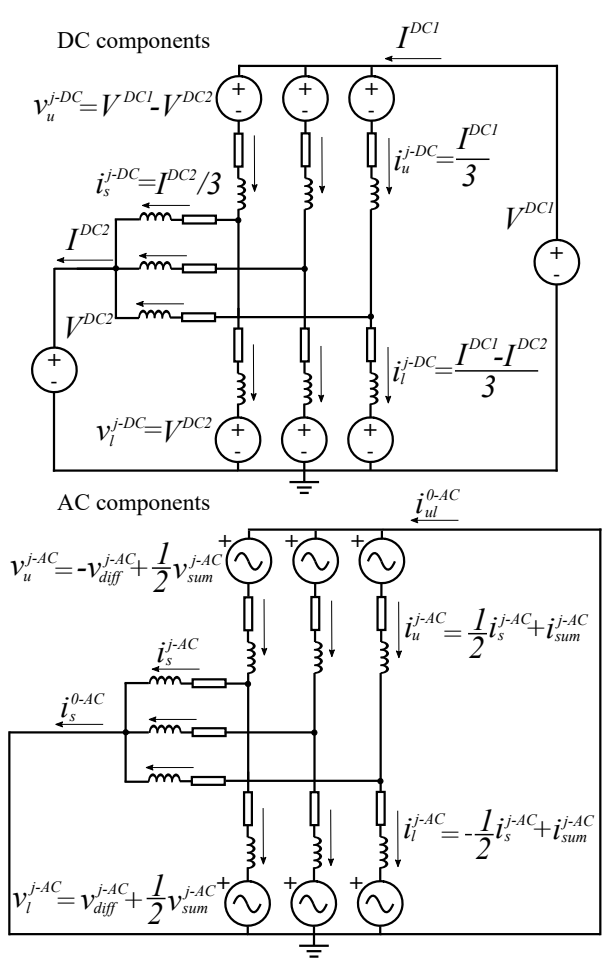

(b) $\mathrm{AC}$ and $\mathrm{DC}$ components
Fig. 1. DC-MMC scheme

- Energy difference between upper and lower arms: this is caused by active power exchange between upper and lower arms, which charges or discharges the SM capacitors of the arms.

- Energy difference between legs: this is caused by active power exchange between legs, which will increase or decrease the energy stored in each leg.

- Total energy: this represents the total energy stored in the SM capacitors, which must be maintained to a specific constant value during the converter operation.

The converter stability is ensured when the total energy is maintained constant and there is energy balance between upper and lower arms and between legs.

1) Energy difference between upper and lower arms: This component is obtained from the power exchanged between upper and lower arms:

$$
\begin{gathered}
P_{u l}^{j}=P_{u}^{j}-P_{l}^{j}=P_{u l}^{j-D C}+P_{u l}^{j-A C}+P_{u l}^{j-\omega}+P_{u l}^{j-2 \omega} \\
\left\{\begin{array}{c}
P_{u l}^{j-D C}=\frac{1}{2} V_{\text {sum }}^{D C} I_{s}^{D C}-2 V_{\text {diff }}^{D C} I_{\text {sum }}^{D C} \\
P_{u l}^{j-A C}=\frac{1}{4} V_{\text {sum }}^{A C} I_{s}^{A C} \cos \left(\phi_{\text {vsum }}^{j}-\phi_{s}^{j}\right)- \\
-V_{\text {diff }}^{A C} I_{\text {sum }}^{A C} \cos \left(\phi_{\text {diff }}^{j}-\phi_{\text {isum }}^{j}\right)
\end{array}\right.
\end{gathered}
$$

where the component $P_{u l}^{j-A C}$ is the same for all phases, unless there is a voltage unbalance, and $P_{u l}^{j-D C}$ is equal to the expression in (8) if power losses are neglected. The DC-MMC shows a constant DC power imbalance between upper and lower arms when active power is transferred through the converter in normal operation. Then, the resulting energy difference, $E_{u l}^{j}=E_{u}^{j}-E_{l}^{j}$, is kept constant if AC power is exchanged between upper and lower arms such that $P_{u l}^{j-A C}=-P_{u l}^{j-D C}$, as mentioned in Section II-B.
2) Energy difference between legs: This component is calculated from the power of each leg:

$$
\begin{gathered}
P_{\text {leg }}^{j}=P_{u}^{j}+P_{l}^{j}=P_{\text {leg }}^{j-D C}+P_{\text {leg }}^{j-A C}+P_{\text {leg }}^{j-\omega}+P_{\text {leg }}^{2 j-\omega} \\
\left\{\begin{array}{c}
P_{\text {leg }}^{j-D C}=V_{\text {sum }}^{D C} I_{\text {sum }}^{D C}-V_{\text {diff }}^{D C} I_{s}^{D C} \\
P_{\text {leg }}^{j-A C}=\frac{1}{2} V_{\text {sum }}^{A C} I_{\text {sum }}^{A C} \cos \left(\phi_{\text {vsum }}^{j}-\phi_{\text {isum }}^{j}\right)- \\
-\frac{1}{2} V_{\text {diff }}^{A C} I_{s}^{A C} \cos \left(\phi_{\text {diff }}^{j}-\phi_{s}^{j}\right)
\end{array}\right.
\end{gathered}
$$

where the component $P_{\text {leg }}^{j-A C}$ is the same for all phases, unless there is a voltage unbalance. It is observed that $P_{\text {leg }}^{j-D C} \simeq 0$, when considering (3) and (7). Also, $P_{\text {leg }}^{j-A C} \simeq 0$, since the angle differences $\phi_{v s u m}^{j}-\phi_{\text {isum }}^{j}$ and $\phi_{\text {diff }}^{j}-\phi_{s}^{j}$ are approximately $\pi / 2$ as indicated in (14). Then, the energy stored in each leg, $E_{\text {leg }}^{j}=E_{u}^{j}+E_{l}^{j}$, is approximately constant.

As a result, in normal operation the energy difference between legs is equal to zero, i.e. $E_{a-b}=E_{\text {leg }}^{a}-E_{\text {leg }}^{b}=0$ and $E_{a-c}=E_{\text {leg }}^{a}-E_{\text {leg }}^{c}=0$. During transient events, such as faults, voltage imbalances can be generated in each leg leading to a DC energy imbalance between legs that must be compensated by the DC-MMC.

3) Total energy: This component is calculated as the sum of the leg energies, i.e. the total energy is approximately constant during normal operation. However, under fault conditions, SM capacitors can be discharged and the total energy must be compensated.

\section{Converter current components}

The currents flowing through the converter can be divided in two main groups: output currents, $i_{s}^{a b c}$, and inner currents, $i_{\text {sum }}^{a b c}$. Table I shows a summary of these current components. 
TABLE I

DESCRIPTION OF CONVERTER CURRENT COMPONENTS

\begin{tabular}{ccl}
\hline Comp. & Freq. & Use \\
\hline \hline$i_{s}$ & AC & Generate AC voltages for upper and lower arms. \\
& DC & $\begin{array}{l}\text { Active power control (normal operation). } \\
\text { Compensate energy imbalance between legs and the } \\
\text { DC links (faults) }\end{array}$ \\
& AC & $\begin{array}{l}\text { Compensate energy imbalance between upper and } \\
\text { lower arms. } \\
\text { Compensate energy imbalance between legs and the } \\
\text { DC links (normal operation). } \\
\text { Active power control (faults). }\end{array}$ \\
& DC
\end{tabular}

1) Output currents: These are the currents flowing to the DC grid 2 and are represented in (4). The DC grid current components, $i_{s}^{j-D C}$, are used to transfer active power through the DC-MMC. In case of faults in DC grid $1, i_{s}^{j-D C}$ are also used to compensate imbalances in the total energy and the energy between legs. The AC grid current components, $i_{s}^{j-A C}$, are used to generate an $\mathrm{AC}$ voltage at the upper and lower arms, which defines a $v_{\text {diff }}^{j-A C}$ at the leg mid points.

Compared to the DC-MMC, in the conventional AC-DC $\mathrm{MMC}$, the DC ouput current components are kept to 0 , while the $\mathrm{AC}$ output current components are used to exchange active and reactive power with an $\mathrm{AC}$ grid.

2) Inner currents: Theses are the circulating currents within the converter and are represented in (5). They are used to balance the internal energy of the DC-MMC. The DC inner currents, $i_{\text {sum }}^{j-D C}$, compensate the total energy of the converter and the energy between legs. In case of faults in DC grid $1, i_{\text {sum }}^{j-D C}$ are also used to control the active power through the DC-MMC. The AC inner currents, $i_{\text {sum }}^{j-A C}$, are used to compensate the steady state energy imbalance in each leg by exchanging $\mathrm{AC}$ power between upper and lower arms.

In the conventional AC-DC MMC, AC and DC inner currents are also used to compensate energy imbalances.

\section{CONVERTER CONTROL}

The design and implementation of the converter control are presented in this Section. The closed-loop control is designed to meet the following objectives:

- Control the active power through the converter.

- Ensure energy balance within the converter.

- Minimize AC circulating currents.

The AC circulating currents are reduced by increasing the AC voltage amplitude up to the maximum value that can be modulated and limiting the reactive power exchange between upper and lower arms. In particular, the angle between AC voltages is used to minimize the AC circulating currents.

The general control scheme is shown in Fig. 2, which is based on the structure presented in [21] for a conventional AC-DC MMC. Then, the control structure of the converter includes the following parts:

- Calculation of output and inner currents references.

- Design of current controllers to regulate AC and DC current references

- Design of energy controllers to balance the total energy of the converter and to ensure that energy difference between upper and lower arms and between legs is zero.

Also, DC fault ride through capability is considered in the converter control design.

\section{A. Current and voltage angles}

Internal $\mathrm{AC}$ power flow is required to balance energy difference between upper and lower arms. However, current and voltage angles of the output and inner AC components are not initially defined. The angle difference between these AC components have an effect on the AC voltage amplitudes and the active and reactive power exchange between upper and lower arms, which is discussed in this Section.

Since arm and phase reactors are mainly inductives $(R \ll$ $X)$, the angle difference between AC currents and voltages is approximately $\pi / 2$ :

$$
\left\{\begin{array}{l}
\phi_{\text {diff }}^{j} \simeq \phi_{s}^{j}+\pi / 2 \\
\phi_{\text {vsum }}^{j} \simeq \phi_{\text {isum }}^{j}-\pi / 2
\end{array}\right.
$$

It is observed that the inner current is leading the inner voltage due to the current direction definition in (5).

1) Active power exchanged between upper and lower arms: The expression in (11) is modified as follows considering the approximation in (14):

$$
\begin{aligned}
P_{u l}^{j-A C}= & \left(\frac{1}{4} V_{\text {sum }}^{A C} I_{s}^{A C}-V_{\text {diff }}^{A C} I_{\text {sum }}^{j-A C}\right) \sin \left(\phi_{\text {vsum }}^{j}-\phi_{\text {diff }}^{j}\right) \\
& =I_{\text {sum }}^{A C} I_{s}^{A C}\left(Z_{s}-\frac{1}{4} Z_{\text {sum }}\right) \sin \left(\phi_{\text {vsum }}^{j}-\phi_{\text {diff }}^{j}\right)
\end{aligned}
$$

where $Z_{s}=V_{\text {diff }}^{A C} / I_{s}^{A C}$ and $Z_{\text {sum }}=V_{\text {sum }}^{A C} / I_{\text {sum }}^{A C}$. Considering that $Z_{s} \gg Z_{\text {sum }}$ [9], [22], the power flow direction of $P_{u l}^{j-A C}$ is determined by the angle difference $\phi_{v s u m}^{j}-\phi_{\text {diff } f}^{j}$. Therefore, the power $P$ defines the active power exchange between upper and lower arms for energy balance, such that:

$$
\left\{\begin{array}{l}
P>0: P_{u l}^{j-D C}=P_{u l}^{j-A C}>0 \& \phi_{\text {vsum }}^{j}-\phi_{\text {diff }}^{j} \in(\pi, 2 \pi) \\
P<0: P_{u l}^{j-D C}=P_{u l}^{j-A C}<0 \& \phi_{\text {vsum }}^{j}-\phi_{\text {diff }}^{j} \in(0, \pi)
\end{array}\right.
$$

2) Reactive power exchanged between upper and lower arms: This power is expressed as follows considering the approximation in (14):

$$
Q_{u l}^{j}=-\left(\frac{1}{4} V_{\text {sum }}^{A C} I_{s}^{A C}+V_{d i f f}^{A C} I_{\text {sum }}^{A C}\right) \cos \left(\phi_{\text {vsum }}^{j}-\phi_{\text {diff }}^{j}\right)
$$

where reactive power exchange is zero when $\phi_{v s u m}^{j}-\phi_{\text {diff }}^{j}=$ $(2 k+1) \pi / 2, \forall k$. It is observed that in this situation the reactive power generated by the arm voltages is different to zero and follows $Q_{u}^{j}=Q_{l}^{j}$.

3) AC voltage amplitudes: These voltages are calculated from the following expressions:

$\left\{\begin{array}{l}V_{u}^{A C^{2}}=V_{\text {diff }}^{A C}{ }^{2}+\frac{1}{2} V_{\text {sum }}^{A C^{2}}-V_{\text {diff }}^{A C} V_{\text {sum }}^{A C} \cos \left(\phi_{\text {vsum }}^{j}-\phi_{\text {diff }}^{j}\right) \\ V_{l}^{A C^{2}}=V_{\text {diff }}^{A C^{2}}+\frac{1}{2} V_{\text {sum }}^{A C^{2}}+V_{\text {diff }}^{A C} V_{\text {sum }}^{A C} \cos \left(\phi_{\text {vsum }}^{j}-\phi_{\text {diff }}^{j}\right)\end{array}\right.$

where it is observed that $V_{u}^{A C}=V_{l}^{A C}$ when $\phi_{\text {vsum }}^{j}-\phi_{\text {diff }}^{j}=$ $(2 k+1) \pi / 2, \forall k$. 


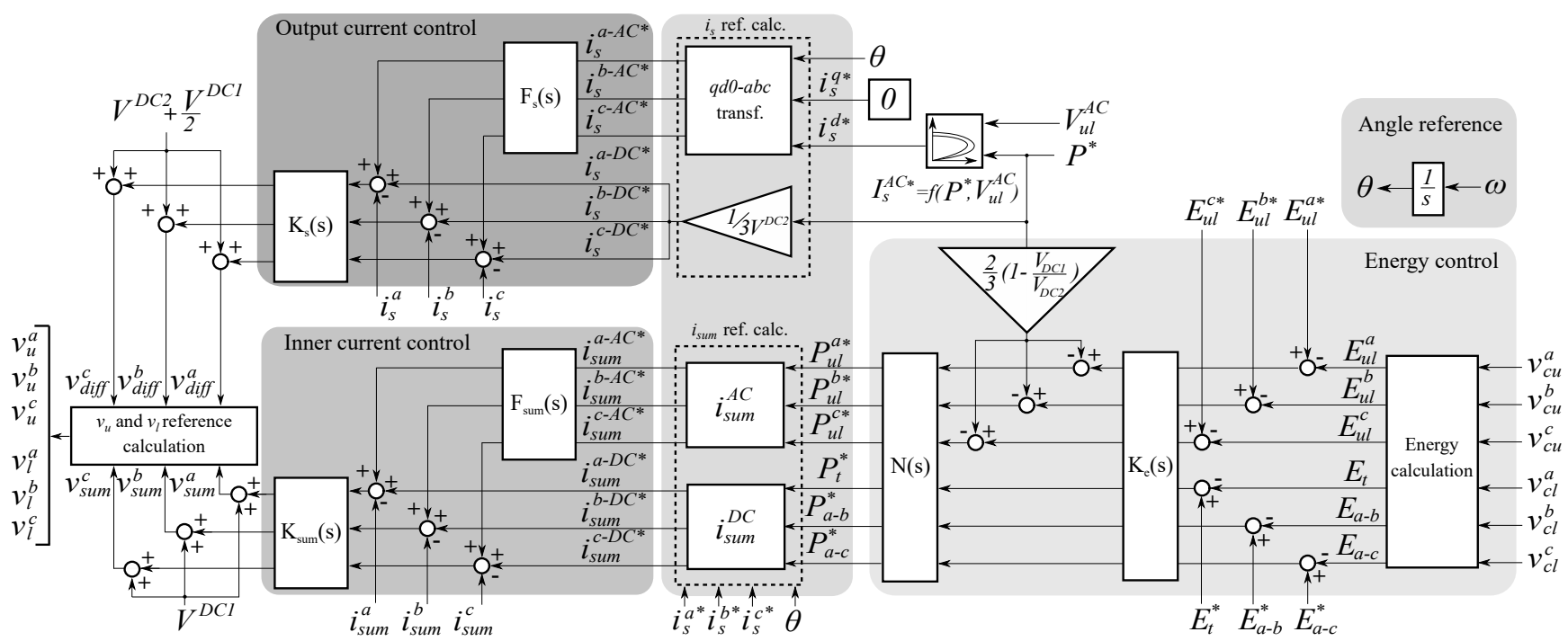

Fig. 2. Complete MMC-DC control scheme in normal operation

4) Minimization of $A C$ circulating current: The reactive power exchange between upper and lower arms is set to zero in order to reduce the AC circulating current. Therefore, the angle difference $\phi_{v s u m}^{j}-\phi_{\text {diff }}^{j}$ is defined as $\pi / 2$ or $3 \pi / 2$ depending on $P$ direction. Fig. 3 shows the angle definition of the AC components if $\phi_{d i f f}^{a}$ is set as $0 \mathrm{rad}$ and assuming approximation in (14).

As a consequence, the $\mathrm{AC}$ voltage magnitudes of upper and lower arms are equal, i.e. $V_{u l}^{A C}=V_{u}^{A C}=V_{l}^{A C}$. This condition is the same that was obtained in [19]. However, in [19] it is assumed that the phase reactors are sufficiently large. In this paper it is proven that this simplification is not required, because the definition of circulating currents, $i_{\text {sum }}^{j}$, using the relations in (3) is considered in the converter analysis.

Also, in order to minimize the AC circulating current, $V_{u l}^{A C}$ is set at the maximum value that can be modulated. In case of a DC-MMC with Full-Bridge (FB) SMs, positive and negative voltages can be modulated and $V_{u l-F B}^{A C}$ is calculated as:

$V_{u l-F B}^{A C}=\min \left(N_{l} V_{S M}-V^{D C 2}, N_{u} V_{S M}-V^{D C 1}+V^{D C 2}\right)$

where $V_{S M}$ is the nominal voltage of a SM. In case of a DCMMC with Half-Brigde (HB) SMs only positive voltages are modulated and $V_{u l-H B}^{A C}$ is calculated as:

$$
\begin{array}{r}
V_{u l-H B}^{A C}=\min \left(N_{l} V_{S M}-V^{D C 2}, N_{u} V_{S M}-V^{D C 1}+V^{D C 2},\right. \\
\left., V^{D C 2}, V^{D C 1}-V^{D C 2}\right)
\end{array}
$$

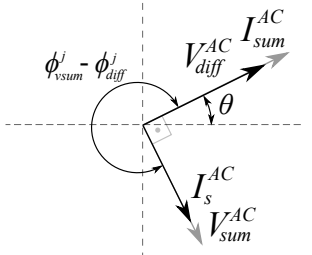

(a) Positive active power $\left(\mathrm{P}^{*}>0\right)$

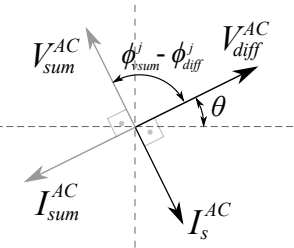

(b) Negative active power $\left(\mathrm{P}^{*}<0\right)$
Fig. 3. Current and voltage angles in terms of active power direction

\section{B. Current reference calculation}

The output and inner currents are controlled in $a b c$-frame. The DC component of the output current reference is calculated based on the active power transferred through the converter, while the $\mathrm{AC}$ components are used to minimize the AC circulating current. The inner currents references are calculated from the energy controllers.

1) DC component of output currents: The reference for this current is calculated as:

$$
i_{s}^{a b c-D C *}=I_{s}^{D C *}=\frac{1}{3} \frac{P^{*}}{V^{D C 2}}
$$

where $P^{*}$ is the active power reference.

2) AC components of output currents: These current references are set in a $q d 0$-frame. The phase reactors, $Z_{s}$, can consume active and reactive power according to $V_{d i f f}^{A C}$. Since $Z_{s}$ is mainly inductive $(R \ll X)$, the active power is not significant compared to the reactive power. Therefore, the $q$ axis current reference is set to zero, $i_{s}^{q *}=0$, and the $d$ axis current reference, $i_{s}^{d^{*}}$, is equal to the AC grid current magnitude, $I_{s}^{A C *}$, which is approximately equivalent to the reactive current consumed by the phase reactors if the active current (i.e. reactor power losses) is neglected.

As a result, the AC current angles $\phi_{s}^{j}$ are defined as shown in Fig. 3 and the angle difference between $\mathrm{AC}$ currents and voltages, $\phi_{\text {diff }}^{j}-\phi_{s}^{j}$, is approximately $\pi / 2$ or $3 \pi / 2$, as mentioned in Section III-A. It should be noted that the reactive current does not produce significant power losses if the phase reactors are designed to be large enough.

The AC grid current reference is used to define the $\mathrm{AC}$ magnitude of upper and lower arms voltages, $V_{u l}^{A C}$, which are equal based on the angle definition presented in Section III-A4. Then, $I_{s}^{A C *}$ is obtained as function of $P^{*}$ and $V_{u l}^{A C}$ from the following biquadratic equation:

$$
\begin{array}{r}
4 Z_{s}^{2}\left(\frac{Z_{s}}{Z_{\text {sum }}}-\frac{1}{4}\right)^{2} I_{s}^{A C *}-4 V_{u l}^{A C^{2}}\left(\frac{Z_{s}}{Z_{\text {sum }}}-\frac{1}{4}\right)^{2} I_{s}^{A C *^{2}}+ \\
+\frac{4 P^{* 2}}{9}\left(1-\frac{V^{D C 2}}{V^{D C 1}}\right)^{2}=0
\end{array}
$$



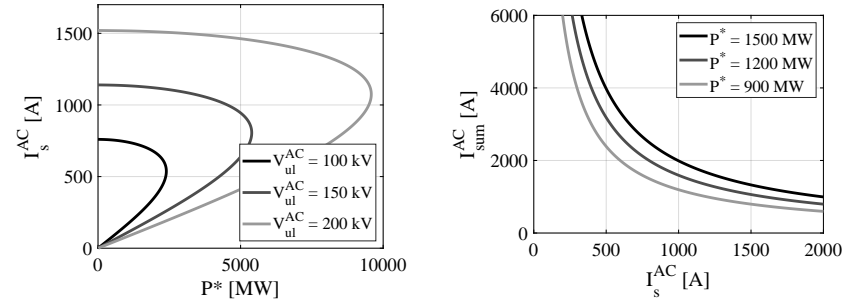

(a) Relation between $I_{s}^{A C}$ and $P^{*}$ for different $V_{u l}^{A C}$

Fig. 4. Converter operation points

(b) Relation between $I_{s}^{A C}$ and $I_{\text {sum }}^{A C}$ for different $P^{*}$

Fig. 4a shows the resulting $I_{s}^{A C *}$ for different values of $P^{*}$ and $V_{u l}^{A C}$. It is observed that two $I_{s}^{A C *}$ are possible per active power $P^{*}$. In order to minimize the total current through each arm, high $I_{s}^{A C *}$ is preferred, which corresponds to low $I_{s u m}^{A C}$, as observed in Fig. 4b.

3) DC components of inner currents: These current references are calculated from the controllers related to the energy difference between legs and the total energy. The DC component of the power through each leg in (13) can be calculated in terms of $i_{\text {sum }}^{j-D C}$ and $i_{s}^{j-D C}(j=a, b, c)$ as:

$$
P_{l e g}^{j-D C}=V^{D C 1} i_{\text {sum }}^{j-D C}+\left(\frac{V^{D C 1}}{2}-V^{D C 2}\right)
$$

Then, the DC inner current references, $i_{\text {sum }}^{j-D *}$, are obtained as function of $P_{t}, P_{a-b}=P_{l e g}^{a-D C}-P_{l e g}^{b-D C}$ and $P_{a-c}=$ $P_{\text {leg }}^{a-D C}-P_{\text {leg }}^{c-D C}$ from the following system of equations:

$$
\begin{aligned}
{\left[\begin{array}{c}
P_{t} \\
P_{a-b} \\
P_{a-c}
\end{array}\right] } & =V^{D C 1}\left[\begin{array}{ccc}
1 & 1 & 1 \\
1 & -1 & 0 \\
1 & 0 & -1
\end{array}\right]\left[\begin{array}{l}
i_{s u m}^{a-D C *} \\
i_{s u m}^{b-D C} \\
i_{\text {sum }}^{c-D C}
\end{array}\right]+ \\
& +\left(\frac{V^{D C 1}}{2}-V^{D C 2}\right)\left[\begin{array}{ccc}
1 & 1 & 1 \\
1 & -1 & 0 \\
1 & 0 & -1
\end{array}\right]\left[\begin{array}{l}
i_{s}^{a-D C *} \\
i_{s}^{b-D C *} \\
i_{s}^{c-D C *}
\end{array}\right.
\end{aligned}
$$

4) AC components of inner currents: These current references are calculated from the controllers related to the energy difference between upper and lower arms. In particular, the magnitude of the AC current references, $I_{\text {sum }}^{j-A C *}$, is calculated from the $\mathrm{AC}$ component of the power exchanged between upper and lower arms, $P_{u l}^{j-A C}$ in (11). If the angle difference $\phi_{\text {vsum }}^{j}-\phi_{\text {diff }}^{j}$ is set as $\pi / 2$ or $3 \pi / 2$, based on the angle conditions in Section III-A4, the sinus component is equal to 1 and $I_{\text {sum }}^{j-A C *}$, is expressed as:

$$
I_{\text {sum }}^{j-A C *}=\frac{P_{u l}^{j-A C}}{I_{s}^{A C *}} \frac{1}{Z_{s}-\frac{1}{4} Z_{\text {sum }}}
$$

Then, the AC inner current references are expressed as:

$$
i_{\text {sum }}^{j-A C *}=I_{\text {sum }}^{j-A C *} \cos \left(\theta+\phi_{\text {isum }}^{j}\right)
$$

\section{Current controllers design}

Grid and inner currents in circuits (4) and (5) are regulated through the same control structure. Proportional-Integral (PI) controllers, $K(s)$, are used to control both the AC and DC current components. A pre-filter, $F(s)$, based on a lead compensator, is used in the AC current references to correct the PI controller action at $\omega$ [21].
The PI gains are calculated based on the inverse-based method [23], which cancels out the current dynamics and introduces a first order dynamic response [21]. Then, the PI controllers for each current component are expressed as:

$$
\begin{gathered}
K_{s}(s)=k_{p-s}+\frac{k_{i-s}}{s} ; K_{\text {sum }}(s)=k_{p-\text { sum }}+\frac{k_{i-s u m}}{s} \\
k_{p-s}=\frac{L}{\tau_{s}} ; k_{i-s}=\frac{R}{\tau_{s}} \\
k_{p-s u m}=\frac{2 L_{a}}{\tau_{\text {sum }}} ; k_{i-\text { sum }}=\frac{2 R_{a}}{\tau_{\text {sum }}}
\end{gathered}
$$

where $K_{p-s}$ and $K_{p-s u m}$ are the proportional gains, $K_{i-s}$ and $K_{i-\text { sum }}$ are the integral gains and $\tau_{s}$ and $\tau_{\text {sum }}$ are the time constants of the current controls.

The pre-filter is expressed as:

$$
\begin{gathered}
F(s)=\alpha K_{f} \frac{s+\omega_{1}}{s+\omega_{2}} ; \alpha=\frac{1+M_{p}}{1-M_{p}} ; \omega_{1}=\omega / \sqrt{\alpha} ; \omega_{2}=\omega \sqrt{\alpha} \\
K_{f}=\frac{1}{M_{t} M_{f}} ; M_{f}=\sqrt{\frac{1+M_{p}}{1-M_{p}}}
\end{gathered}
$$

where $M_{t}$ is the gain correction and $M_{p}$ is the phase correction, which are calculated for each current control system.

\section{Energy control}

The energy control is based on six controllers that regulate the energy components of the DC-MMC: one for the total energy, $E_{t}$, two for the energy difference between legs, $E_{a-b}$ and $E_{a-c}$, and three for the energy difference between upper and lower arms, $E_{u l}^{a}, E_{u l}^{b}$ and $E_{u l}^{c}$. These controllers provide the power references associated to the inner current references described in Sections III-B3 and III-B4.

The energy controllers are designed based on the conventional structure of an one-degree-of-freedom control configuration shown in Fig. 5. Notch filters, $N(s)$, are used to cancel ripples in the power references at $\omega$ and $2 \omega$, which could be amplified by the inner current control. These ripples are caused by active power of upper and lower arms, as explained in Section II-C. The Notch filters are based on a second order structure and are expressed as:

$$
N(s)=\frac{s^{2}+\omega_{n}^{2}}{1+2 \omega_{n} / Q+\omega_{n}^{2}}
$$

where $\omega_{n}$ is the AC frequency to be eliminated, i.e. $\omega$ or $2 \omega$, and $Q$ is the quality factor, which is set as 3 [21].

The inner current control dynamics are represented in $G_{\text {isum }}(s)$ as:

$$
G_{i s u m}(s)=\frac{1}{1+\tau_{\text {sum }} s}
$$

where $\tau_{\text {sum }}$ is the equivalent time constant of the inner current control.

The energy controllers, $K_{e}(s)$, are based on PI controllers to regulate the mean value of the energy components:

$$
K_{e}(s)=K_{p-e}+\frac{K_{i-e}}{s}
$$

where $K_{p-e}$ and $K_{i-e}$ are the proportional and integral control gains of the energy controllers. The control design is 


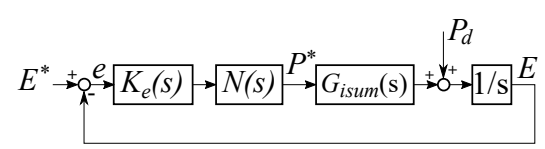

Fig. 5. One-degree-of-freedom control configuration to design energy controllers

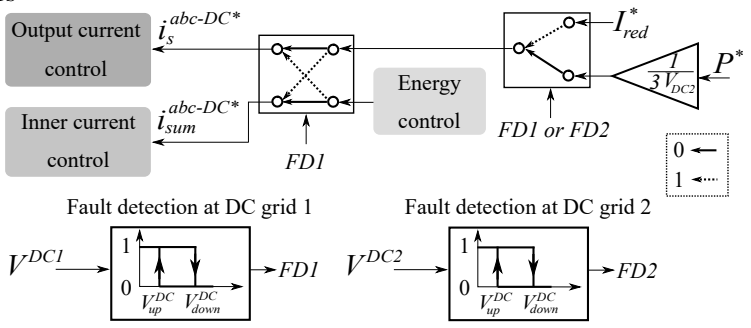

Fig. 6. Control structure modification for DC faults.

based on a disturbance rejection problem, i.e. considering the disturbance power $P_{d}$ in Fig. 5. The controller is designed to have a maximum error of $10 \%$, a maximum control action, $P^{*}$, of 1.1 of the nominal power and a settling time of $1 \mathrm{~s}$.

\section{E. DC fault ride through}

During a DC fault the converter must remain connected and provide fault blocking capability. This operation is only possible if FB SMs are used, because such SMs can generate negative DC voltages to reduce the fault current. DC faults are blocked using the control structure in Fig. 2 presented for normal operation. However, modifications in Fig. 6 are required to ensure that $\mathrm{DC}$ fault current through the converter is controlled and total energy and energy difference between legs are balanced. Control of energy difference between upper and lower arms is not modified since it is an internal energy balance of the converter.

In relation to pole-to-ground faults in DC grid 1, lower arm SMs apply the nominal voltage of DC grid $2, v_{l}^{j-D C}=$ $V^{D C 2}$, while upper arm SMs apply the necessary DC voltage, $v_{u}^{j-D C}=V_{r e d}^{D C 2}-V^{D C 2}$, to block the faults and define a reduced DC fault current, $I_{\text {red }}^{*}$ in Fig. 6. In this case, the DC components of the converter currents must change their roles, as shown in Fig. 6 when $F D 1=1$, because $i_{s u m}^{j-D C}$ cannot be used to balance the energy. Therefore, $i_{s}^{j-D C}$ is used to balance the energy and $i_{\text {sum }}^{j-D C}$ sets the reduced current $I_{r e d}^{*}$.

In relation to pole-to-ground faults in DC grid 2, lower arm SMs apply a reduced DC fault voltage, $v_{l}^{j-D C}=V_{\text {red }}^{D C 2}$, which blocks the faults and is used to define the reduced fault current, $I_{\text {red. }}^{*}$. Upper arm SMs apply the necessary DC voltage, $v_{u}^{j-D C}=V^{D C 2}-V_{\text {red }}^{D C 2}$, to compensate the reduction from the lower arm SMs. In this case, $i_{s}^{j-D C}$ is used to define $I_{\text {red }}^{*}$, while $i_{\text {sum }}^{j-D C}$ can still be used to balance the converter energy because the necessary power to maintain the energy balance is from DC grid 1.

DC fault currents can be regulated to zero, which is preferred to open DC circuit breakers and disconnectors, or to a reduced value different to zero, $I_{\text {red }}^{*}$, which may be convenient in DC protection schemes based on discrimination strategies as indicated in [24].

\section{F. Comparison with other control schemes}

The control structure presented in this paper is compared with other schemes from the literature, as shown in Table II.
All the control schemes presented in the literature include an AC circulating current control except in [15], [19], where only DC output current is regulated. In relation to energy balancing, all the control structures include at least a control for the energy difference between upper and lower arms. Most of the references implement this energy control using the sum of the capacitor voltages, $v_{c u}^{a b c}$ and $v_{c l}^{a b c}$, except for [9], [20] and this paper, which use the associated energy calculation, $E_{u l}^{a b c}$. Also, a full regulation of all energy components and currents is only presented in [9], [20] and this paper.

Conditions to minimize $\mathrm{AC}$ circulating current are presented in all control schemes except [13]. In particular, [11], [16], [18] assume that $\mathrm{AC}$ circulating current is minimized only maximizing the available AC arm voltages. In [19] an additional condition to minimize $\mathrm{AC}$ circulating currents is obtained from the mathematical formulation of current flow between upper and lower arms, which is equivalent to the condition derived in this paper and is also used in [9], [20].

In terms of DC fault analysis, [11], [18] suggest DC fault blocking capability, but it is achieved applying a reversed DC voltage without a close-loop control. This paper provides DC fault ride through response including a DC fault current control and ensuring energy balancing.

TABLE II

COMPARISON OF DIFFERENT CONTROL SCHEMES IN THE LITERATURE

\begin{tabular}{|c|c|c|c|c|}
\hline Function & $\begin{array}{l}\text { Control of } \\
\text { conv. } \\
\text { currents }\end{array}$ & $\begin{array}{l}\text { Energy } \\
\text { Control }\end{array}$ & $\begin{array}{l}\text { DC fault } \\
\text { capability }\end{array}$ & $\begin{array}{l}\text { AC circ. } \\
\text { current min. }\end{array}$ \\
\hline $\begin{array}{l}\text { This } \\
\text { paper }\end{array}$ & $\begin{array}{l}\text { All } \\
\text { current } \\
\text { comp. }\end{array}$ & $\begin{array}{l}\text { All } \\
\text { energy } \\
\text { comp. }\end{array}$ & $\begin{array}{l}\text { Full ctrl. of } \\
\text { DC fault } \\
\text { currents }\end{array}$ & Yes \\
\hline $\begin{array}{l}\text { Yang } \\
{[15],[19]}\end{array}$ & $\begin{array}{l}\text { DC output } \\
\text { current. }\end{array}$ & $\begin{array}{l}\text { Energy } \\
\text { diff. arms }\end{array}$ & No & Yes \\
\hline $\begin{array}{l}\text { Kish } \\
{[16],[18]}\end{array}$ & $\begin{array}{l}\text { AC circ. } \\
\text { currents }\end{array}$ & $\begin{array}{l}\text { Energy } \\
\text { diff. arms }\end{array}$ & $\begin{array}{l}\text { Only DC fault } \\
\text { blocking cap. }\end{array}$ & Yes \\
\hline $\begin{array}{l}\text { Li [9], } \\
{[20]}\end{array}$ & $\begin{array}{l}\text { All } \\
\text { current } \\
\text { comp. }\end{array}$ & $\begin{array}{l}\text { All } \\
\text { energy } \\
\text { comp. }\end{array}$ & No & Yes \\
\hline Du [13] & $\begin{array}{l}\text { All } \\
\text { current } \\
\text { comp. }\end{array}$ & $\begin{array}{l}\text { Energy } \\
\text { diff. arms }\end{array}$ & No & No \\
\hline $\begin{array}{l}\text { Jovcic } \\
{[11]}\end{array}$ & $\begin{array}{l}\text { All } \\
\text { current } \\
\text { comp. }\end{array}$ & $\begin{array}{l}\text { Energy } \\
\text { diff. arms }\end{array}$ & $\begin{array}{l}\text { Only DC fault } \\
\text { blocking cap. }\end{array}$ & Yes \\
\hline
\end{tabular}

\section{CASE STUDY}

The DC-MMC control is validated through time-domain simulations in Matlab Simulink. The system and control parameters used in this case study are shown in Tables III and IV. The frequency of the inner AC components is chosen as $\omega=2 \pi 50 \mathrm{rad} / \mathrm{s}$, but higher frequency of AC components could be used to reduce the size of the reactors and the SM capacitors [10]. Also, in this case study it is assumed that the SMs are FB and $N=N_{u}=N_{l}$. Therefore, considering that the energy stored in upper and lower arms is the same and the energy stored in the converter is $40 \mathrm{~kJ} / \mathrm{MVA}$ [6], the capacitors $C_{u}$ and $C_{l}$ are calculated.

\section{A. Normal Operation}

The power is transferred from DC Grid 1 to 2 following a ramp variation from 0 to nominal power during $0.1 \mathrm{~s}$. Then, a 
TABLE III

SYSTEM PARAMETERS FOR THE CASE STUDY

\begin{tabular}{cccc}
\hline Magnitudes & Symbol & Value & Units \\
\hline \hline Nominal Power & $\mathrm{P}$ & 1.5 & $\mathrm{GW}$ \\
\hline Voltage of HVDC Grid 1 & $V^{D C 1}$ & 300 & $\mathrm{kV}$ \\
\hline Voltage of HVDC Grid 2 & $V^{D C 2}$ & 400 & $\mathrm{kV}$ \\
\hline Phase reactor inductance & $L_{s}$ & 400 & $\mathrm{mH}$ \\
\hline Phase reactor resistance & $R_{s}$ & 0.01 & $\Omega$ \\
\hline Arm reactor inductance & $L_{a}$ & 38 & $\mathrm{mH}$ \\
\hline Arm reactor resistance & $R_{a}$ & 0.6 & $\Omega$ \\
\hline Num. of SMs & $N$ & 250 & $\mathrm{SM}$ \\
\hline Nom. Voltage of SMs & $V_{S M}$ & 2 & $\mathrm{kV}$ \\
\hline Upper arm capacitance & $C_{u}$ & 0.5 & $\mathrm{~F}$ \\
\hline Lower arm capacitance & $C_{l}$ & 0.055 & $\mathrm{~F}$ \\
\hline AC components frequency & $\omega$ & $2 \pi 50$ & $\mathrm{rad} / \mathrm{s}$ \\
\hline & & &
\end{tabular}

TABLE IV

CONTROL PARAMETERS FOR THE CASE STUDY

\begin{tabular}{lc}
\hline Control parameters & Value \\
\hline \hline$K_{s}: k_{p-s}, k_{i-s}$ & $20.95,15$ \\
\hline$K_{s u m}: k_{p-s u m}, k_{i-s u m}$ & 76,1200 \\
\hline$F_{s}: M_{t-s}, M_{p-s}$ & $0.1572,0.9876$ \\
\hline$F_{s u m}: M_{t-s u m}, M_{p-s u m}$ & $0.954,0.3$ \\
\hline$K_{e}: k_{p-e}, k_{i-e}$ & 50,250 \\
\hline
\end{tabular}

power step variation is applied at nominal reversal value. The time-domain simulations are shown in Fig. 7, where power starts to increase at $1 \mathrm{~s}$ and the power step is applied at $2 \mathrm{~s}$.

Figs. 7b-c show that the upper and lower arm voltages can reach negative values, due to the use of FB SMs, and that the AC voltage amplitudes are defined by (19). Figs. $7 \mathrm{~g}$-h show the sum of the capacitor voltages, $v_{c u}^{j}$ and $v_{c l}^{j}$, where it is observed that the $\mathrm{AC}$ voltages have components at $\omega$ and $2 \omega$ (i.e. 50 $\mathrm{Hz}$ and $100 \mathrm{~Hz}$ ), which are caused by the active power of upper and lower arms, and that the AC voltage amplitudes are different for upper and lower arm capacitors due to $C_{u}>C_{l}$. Figs. 7d-e show the currents through the arms and the phase reactors, where it is observed that the $\mathrm{AC}$ components of the phase reactor currents are defined by $V_{\text {diff }}^{A C}$ and the impedances $Z_{s}$ and $Z_{a}$, such that $I_{s}^{A C}=V_{\text {diff }}^{A C} /\left(Z_{s}+Z_{a}\right)$.

Table $\mathrm{V}$ shows the AC circulating current minimization based on the value of $\phi_{\text {diff }}^{j}-\phi_{\text {vsum }}^{j}$ when $P^{*}>0$ and $V_{u}^{A C}=200 \mathrm{kV}$. It is clear that when $\phi_{\text {diff }}^{j}-\phi_{\text {vsum }}^{j}=\pi / 2 \mathrm{rad}$ the AC circulating currents, $I_{\text {sum }}^{A C}$, are minimum and reactive power exchange between upper and lower arms is zero, i.e. reactive power is equally distributed between upper and lower arms.

TABLE V

RESUlTS FOR ANGLES $\phi_{v}=\phi_{\text {diff }}^{j}-\phi_{\text {vsum }}^{j}$ WHEN $P^{*}>0$ AND $V_{u}^{A C}=200 \mathrm{KV}$

\begin{tabular}{lllll}
\hline$\phi_{v}(\mathrm{rad})$ & $I_{\text {sum }}^{A C}(\mathrm{kA})$ & $Q_{u}^{j}(\mathrm{Mvar})$ & $Q_{l}^{j}(\mathrm{Mvar})$ & $Q_{u l}^{j}$ (Mvar) \\
\hline \hline$\pi / 6$ & 2.33 & 107 & -362 & 469 \\
\hline$\pi / 4$ & 1.73 & 30 & -241 & 271 \\
\hline$\pi / 3$ & 1.45 & -16 & -173 & 157 \\
\hline$\pi / 2$ & 1.31 & -86 & -86 & 0 \\
\hline $2 \pi / 3$ & 1.58 & -162 & -5 & 157 \\
\hline $3 \pi / 4$ & 2.01 & -222 & 48 & 270 \\
\hline $5 \pi / 6$ & 3.07 & -340 & 123 & 463 \\
\hline
\end{tabular}

\section{B. Fault Operation}

A temporarily fault of $1 \mathrm{~s}$ is tested at DC grid 1 and 2 . The time-domain simulations are shown in Figs. 8 and 9, where

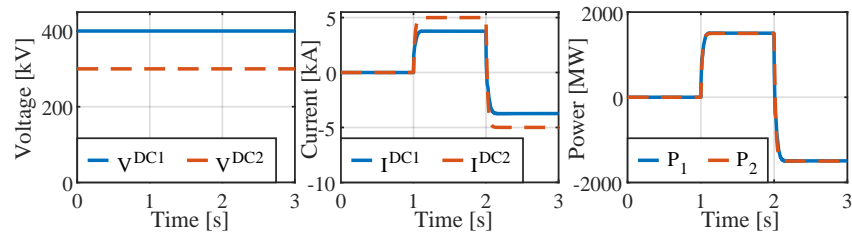

(a) DC voltage, DC current and active power

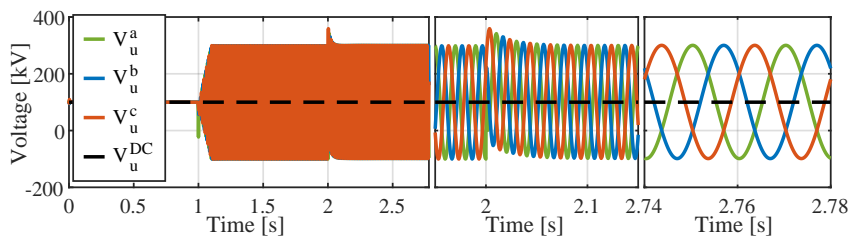

(b) Voltages $v_{u}^{a b c}$

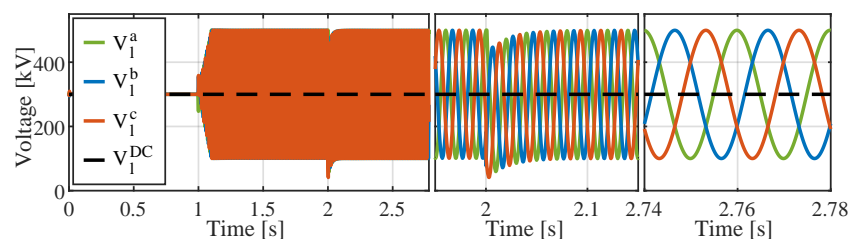

(c) Voltages $v_{l}^{a b c}$

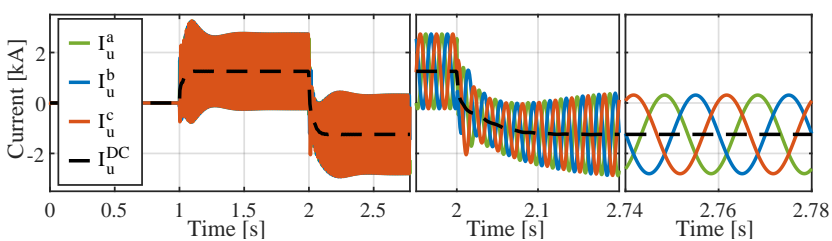

(d) Currents $i_{u}^{a b c}$

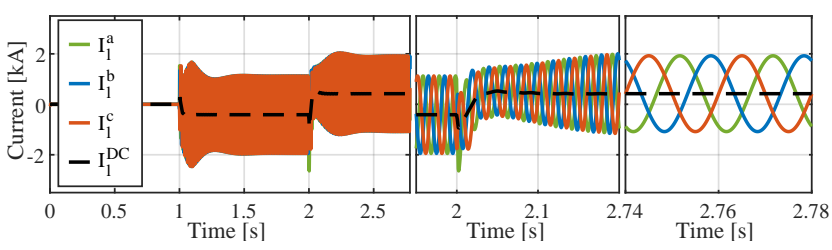

(e) Currents $i_{l}^{a b c}$

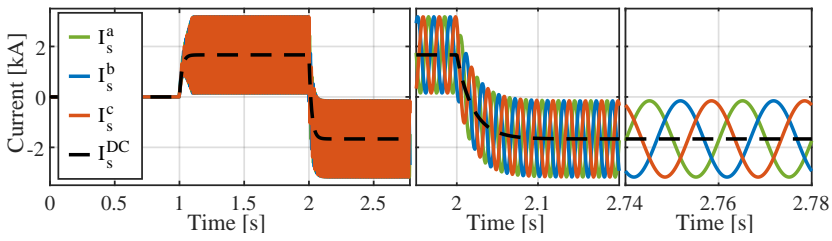

(f) Currents $i_{s}^{a b c}$

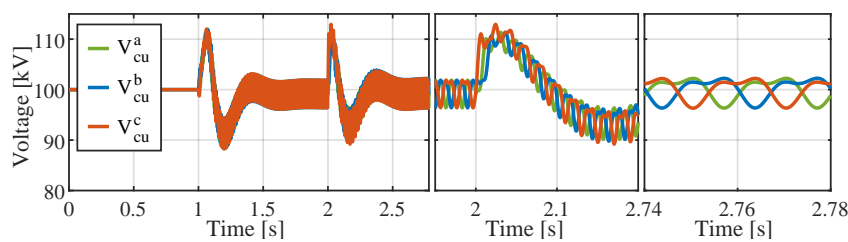

(g) Voltages $v_{c u}^{a b c}$

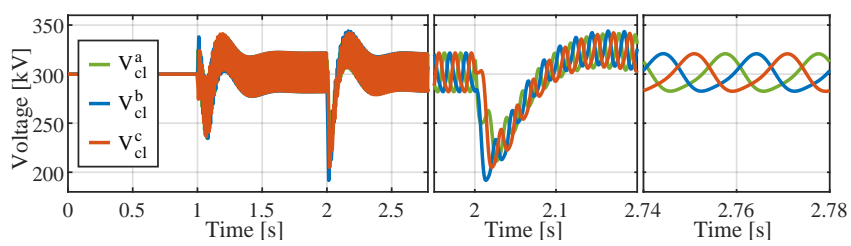

(h) Voltages $v_{c l}^{a b c}$

Fig. 7. Results for normal operation 
the faults are applied at $2 \mathrm{~s}$, and the steady state values before and during the faults are detailed in Table VI.

The results verify that the DC-MMC withstands a temporarily fault keeping the energy constant, as seen from the sum of capacitor voltages in Figs. 8g-h and $9 \mathrm{~g}-\mathrm{h}$. It is observed that $v_{c l}^{a b c}$ is $20 \%$ higher than the nominal value for a short period of time, when DC faults are applied. Similar capacitor voltage variations under fault conditions are reported in the literature [6], [11]. In these conditions, the converter operates in a degraded mode, where the DC current is reduced to $I_{\text {red }}^{*}=0$, as seen in Figs. 8a and 9a. Also, the results show that the transient response of arm currents and voltages is improved compared to DC fault blocking only applying a reversed DC voltage, as presented in [11].

TABLE VI

STEADY STATE RESULTS

\begin{tabular}{lllll}
\hline Components & $\begin{array}{l}\text { Normal } \\
\text { operation }\end{array}$ & $\begin{array}{l}\text { Fault at DC } \\
\text { grid 1 }\end{array}$ & $\begin{array}{l}\text { Fault at DC } \\
\text { grid 2 }\end{array}$ & Units \\
\hline \hline$I^{D C 1}, I^{D C 2}$ & $3.762,5$ & 0,0 & 0,0 & $\mathrm{kA}$ \\
\hline$P^{D C 1}, P^{D C 2}$ & $1.505,1.500$ & 0,0 & 0,0 & $\mathrm{GW}$ \\
\hline$v_{u}^{D C}, v_{l}^{D C}$ & 100,300 & $-300,300$ & 400,0 & $\mathrm{kV}$ \\
\hline$V_{u}^{A C}, V_{l}^{A C}$ & 200,200 & 200,200 & 100,100 & $\mathrm{kV}$ \\
\hline$v_{c u}^{D C}, v_{c u}^{D C}$ & 100,300 & 100,300 & 100,300 & $\mathrm{kV}$ \\
\hline$i_{u}^{D C}, i_{l}^{D C}$ & $1.254,-0.412$ & 0,0 & 0,0 & $\mathrm{kA}$ \\
\hline$I_{u}^{A C}, I_{l}^{A C}$ & $1.480,1.535$ & $0.750,0.750$ & $0.377,0.377$ & $\mathrm{kA}$ \\
\hline$i_{s}^{D C}$ & 1.666 & 0 & 0 & $\mathrm{kA}$ \\
\hline$I_{s}^{A C}$ & 1.5 & 1.5 & 0.755 & $\mathrm{kA}$ \\
\hline
\end{tabular}

\section{Conclusion}

The DC-MMC has been analyzed in detail as a potencial non-isolated topology to interconnect HVDC systems at different voltage levels. The main structure of this converter is similar to a conventional AC-DC MMC, but the operation presents important differences.

An energy-based closed-loop control has been presented to have a full regulation of the current and energy components in normal and fault operation. Energy imbalance between upper and lower arms must be continuously compensated by AC circulating currents, which increases power losses. An adequate calculation of current references was included to minimize AC circulating currents. This was achieved with a proper angle definition between $\mathrm{AC}$ voltages, which reduces reactive power exchange between upper and lower arms, and setting the AC magnitude of the arm voltages at the maximum value allowed by modulation. Also, the control was modified to have DC fault ride through capability for faults applied at both sides of the converter. Energy can be balanced under fault conditions, which allows the converter to remain connected and control the DC fault current.

As a result, the DC-MMC operation using FB SMs is validated in a time-domain simulation, showing a correct active power transfer between the DC links while keeping energy balance and a proper DC fault ride through capability.

\section{REFERENCES}

[1] D. V. Hertem, O. Gomis-Bellmunt, and J. Liang, HVDC Grids: For Offshore and Supergrid of the Future. Wiley-IEEE Press, 2016.

[2] J. D. Paez, D. Frey, J. Maneiro, S. Bacha, and P. Dworakowski, "Overview of dc-dc converters dedicated to hvdc grids," IEEE Trans. on Power Delivery, pp. 1-1, 2018.

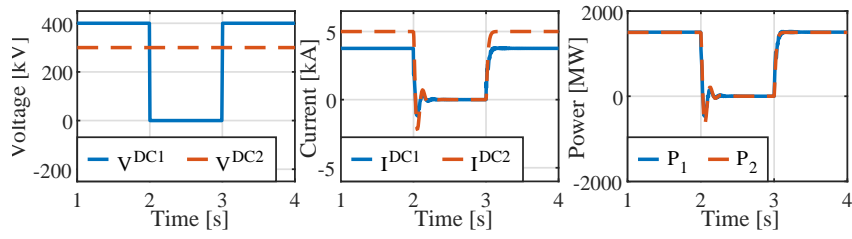

(a) DC voltage, DC current and active power

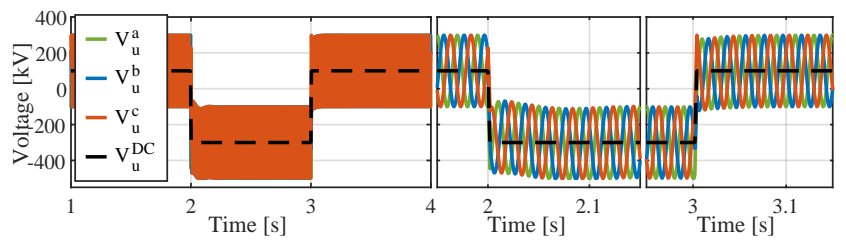

(b) Voltages $v_{u}^{a b c}$

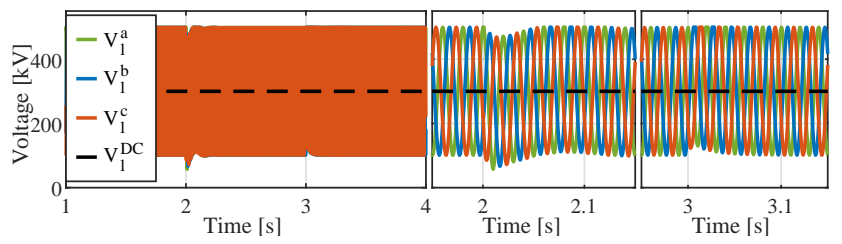

(c) Voltages $v_{l}^{a b c}$

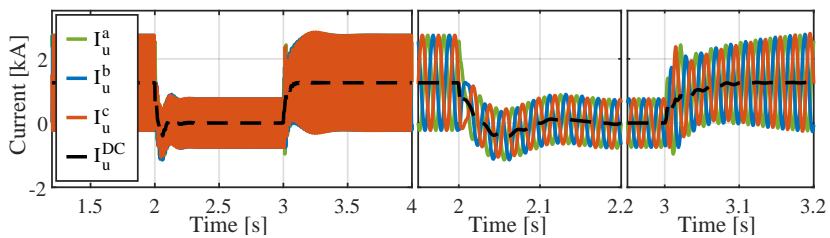

(d) Currents $i_{u}^{a b c}$

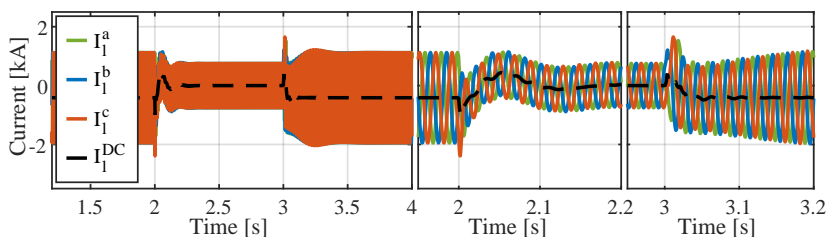

(e) Currents $i_{l}^{a b c}$

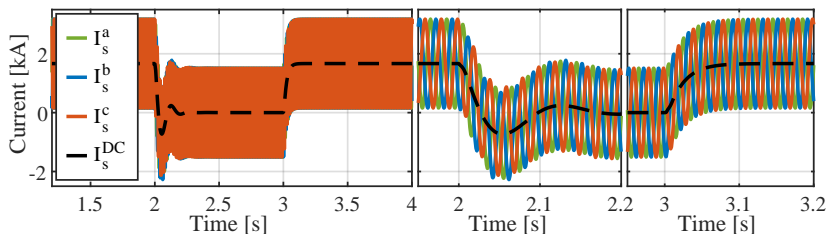

(f) Currents $i_{s}^{a b c}$

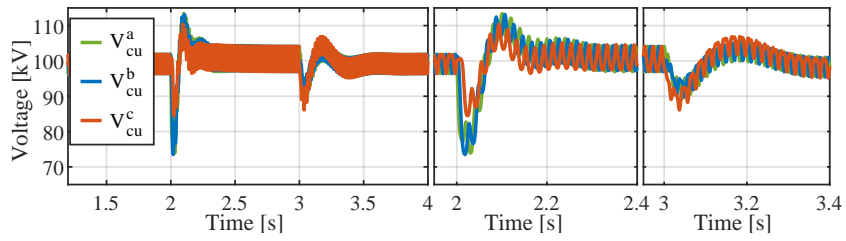

(g) Voltages $v_{c u}^{a b c}$

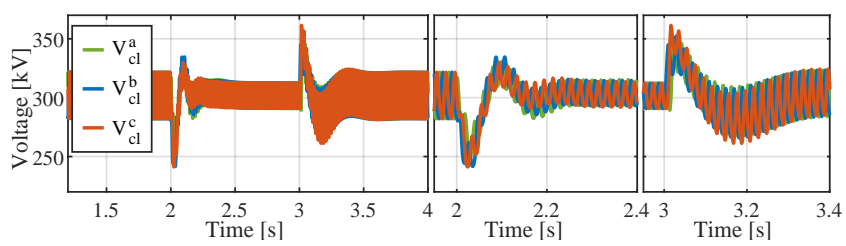

(h) Voltages $v_{c l}^{a b c}$

Fig. 8. Results under fault at DC grid 1 


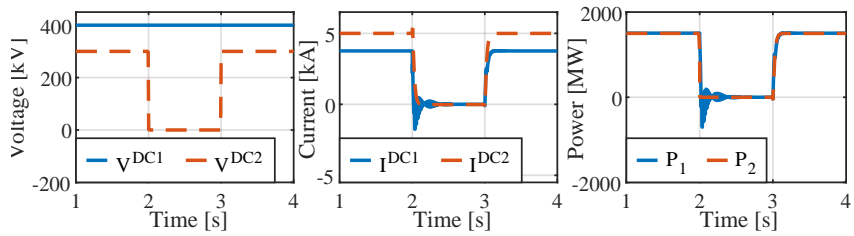

(a) DC voltage, DC current and active power

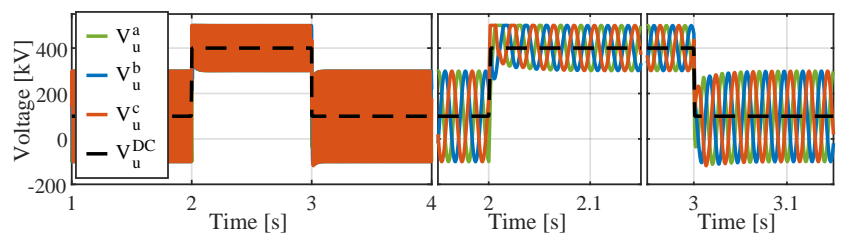

(b) Voltages $v_{u}^{a b c}$

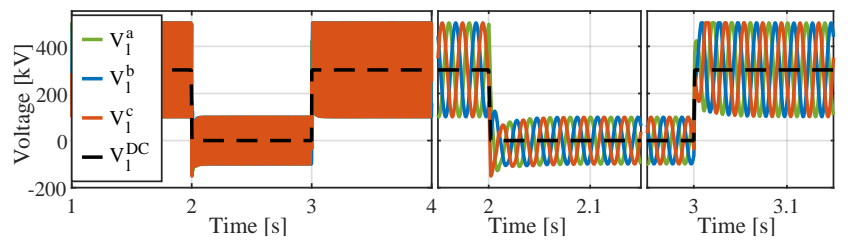

(c) Voltages $v_{l}^{a b c}$

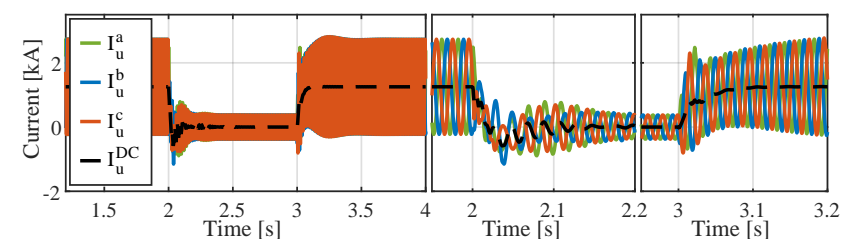

(d) Currents $i_{u}^{a b c}$

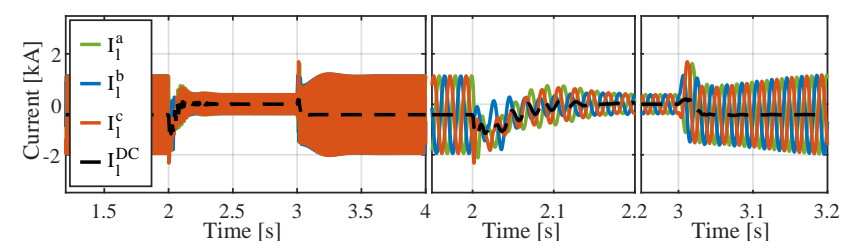

(e) Currents $i_{l}^{a b c}$

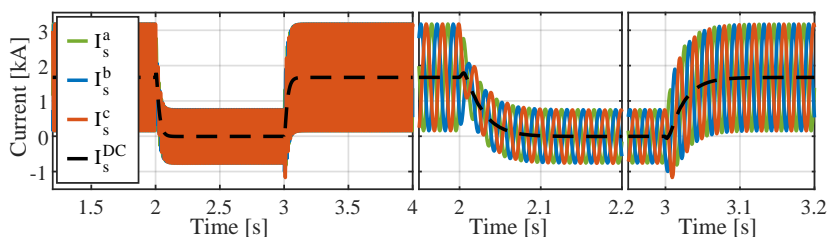

(f) Currents $i_{s}^{a b c}$

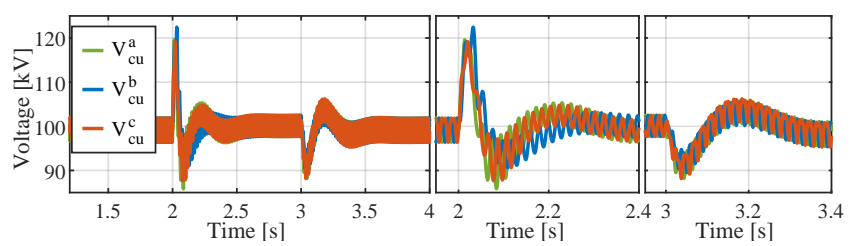

(g) Voltages $v_{c u}^{a b c}$

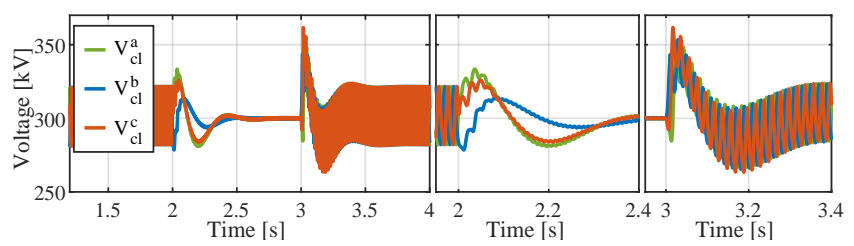

(h) Voltages $v_{c l}^{a b c}$
[3] A. Schön and M. Bakran, "Comparison of modular multilevel converter based hv dc-dc-converters," in 2016 18th European Conf. on Power Elec. and Applications, Sept 2016, pp. 1-10.

[4] G. J. Kish, "On the Emerging Class of Non-Isolated Modular Multilevel DC-DC Converters for DC and Hybrid AC-DC Systems," 2017.

[5] J. D. Páez, J. Maneiro, P. Dworakowski, D. Frey, and S. Bacha, "DC-DC Converters for HVDC Grids : A Survey," International Conference on Components and Systems for DC Grids, p. 14, 2017.

[6] K. Sharifabadi, L. Harnefors, H. P. Nee, S. Norrga, and R. Teodorescu, Design, control and application of modular multilevel converters for HVDC transmission systems. Wiley, 2016.

[7] S. Norrga, L. Angquist, and A. Antonopoulos, "The polyphase cascadedcell DC/DC converter," in 2013 IEEE Energy Conversion Congress and Exposition, ECCE 2013, 2013.

[8] J. A. Ferreira, "The multilevel modular DC converter," IEEE Trans. on Power Elec., vol. 28, no. 10, pp. 4460-4465, 2013.

[9] Y. Li, F. Gruson, P. Delarue, and P. L. Moigne, "Design and control of modular multilevel dc converter (m2dc)," in 2017 19th European Conf. on Power Elec. and Applications, Sept 2017, pp. P.1-P.10.

[10] H. Yang, J. Qin, S. Debnath, and M. Saeedifard, "Phasor Domain Steady-State Modeling and Design of the DC-DC Modular Multilevel Converter," IEEE Trans. on Power Delivery, vol. 31, no. 5, pp. 20542063, oct 2016

[11] D. Jovcic, P. Dworakowski, G. Kish, A. Jamshidifar, A. Nami, A. Darbandi, and X. Guillaud, "Case Study of Non-Isolated MMC DC-DC Converter in HVDC Grids," in CIGRE Symp., Aalborg, 2019, pp. 1-7.

[12] K. Huang and J. A. Ferreira, "Two operational modes of the modular multilevel DC converter," in 9th International Conference on Power Electronics - ECCE Asia: "Green World with Power Electronics". IEEE Inc., jul 2015, pp. 1347-1354.

[13] S. Du, B. Wu, K. Tian, D. Xu, and N. R. Zargari, "A Novel MediumVoltage Modular Multilevel DC-DC Converter," IEEE Trans. on Industrial Elec., vol. 63, no. 12, pp. 7939-7949, dec 2016.

[14] B. Li, S. Shi, Y. Zhang, R. Yang, G. Wang, and D. Xu, "Analysis of the operating principle and parameter design for the modular multilevel DC/DC converter," in 9th International Conference on Power Electronics - ECCE Asia: "Green World with Power Electronics". IEEE Inc., jul 2015, pp. 2832-2837.

[15] H. Yang and M. Saeedifard, "A Capacitor Voltage Balancing Strategy with Minimized AC Circulating Current for the DC-DC Modular Multilevel Converter," IEEE Trans. on Industrial Elec., 2017.

[16] G. J. Kish, P. W. Lehn, C. Holmes, P. W. Lehn, M. Ranjram, and P. W. Lehn, "A Comparison of Modular Multilevel Energy Conversion Processes : DC / AC versus DC / DC," IEEE Trans. on Power Delivery, vol. 30, no. c, pp. 951-958, 2014.

[17] G. J. Kish and P. W. Lehn, "Modeling Techniques for Dynamic and Steady-State Analysis of Modular Multilevel DC/DC Converters," IEEE Trans. on Power Delivery, vol. 31, no. 6, pp. 2502-2510, dec 2016.

[18] G. J. Kish, M. Ranjram, and P. W. Lehn, "A Modular Multilevel DC/DC Converter With Fault Blocking Capability for HVDC Interconnects," IEEE Trans. on Power Elec., vol. 30, no. 1, pp. 148-162, jan 2015.

[19] H. Yang, M. Saeedifard, and A. Yazdani, "An Enhanced Closed-Loop Control Strategy With Capacitor Voltage Elevation for the DC-DC Modular Multilevel Converter," IEEE Trans. on Industrial Elec., vol. 66, no. 3, pp. 2366-2375, mar 2019.

[20] F. Gruson, Y. Li, P. Delarue, P. Le Moigne, F. Colas, and X. Guillaud, "Full State Regulation of the Modular Multilevel DC converter (M2DC) achieving minimization of circulating currents," IEEE Trans. on Power Delivery, pp. 1-1, sep 2019.

[21] E. Prieto-Araujo, A. Junyent-Ferré, C. Collados-Rodríguez, G. ClarianaColet, and O. Gomis-Bellmunt, "Control design of Modular Multilevel Converters in normal and AC fault conditions for HVDC grids," Electric Power Systems Research, vol. 152, pp. 424-437, 2017.

[22] H. Yang and M. Saeedifard, "Closed-loop Control of the DC-DC Modular Multilevel Converter," IEEE Energy Conversion Congress and Exposition (ECCE), no. Mmc, 2016.

[23] L. Harnefors and H.-P. Nee, "Model-based current control of AC machines using the internal model $\backslash$ ncontrol method," IEEE Trans. on Industry Applications, vol. 34, no. 1, pp. 133-141, 1998.

[24] G. Chaffey, P. D. Judge, M. M. C. Merlin, P. R. Clemow, and T. C. Green, "DC fault ride through of multilevel converters," in 2016 IEEE Energy Conv. Congress and Exp. (ECCE). IEEE, sep 2016, pp. 1-6.

Fig. 9. Results under fault at DC grid 2. 